\title{
Uso de automóveis e qualidade de vida urbana: desafios para a psicologia
}

\author{
Ingrid Luiza Neto \\ Universidade de Brasília \\ Zuleide de Oliveira Feitosa \\ Seminário Presbiteriano de Brasília - Mackenzie \\ Fabio Henrique Vieira de Cristo \\ Centro Universitário de Brasília e Instituto de Educação Superior de Brasília \\ Clara Brasiliana Cantal \\ Universidade Victoria de Wellington, Nova Zelândia \\ Hartmut Günther \\ Instituto de Psicologia da Universidade de Brasilia
}

$\mathrm{N}$ esse artigo, apresentamos uma resenha do livro Threats from car traffic to the quality of urban life: Problems, causes, and solutions ${ }^{1}$ (Gärling \& Steg, 2007), que se propõe a discutir as causas e os impactos decorrentes do uso do automóvel e indicar estratégias para minimizar os efeitos negativos desse comportamento. A obra enfatiza que o aumento do uso de veículos motorizados é um dos grandes responsáveis por problemas ambientais globais, impactando negativamente a qualidade de vida urbana e que, para minimizar esses impactos, faz-se necessário compreender os aspectos que contribuem para a manutenção desse comportamento. Desta forma, buscou aprofundar o conhecimento de como a psicologia tem atuado ou pode desenvolver práticas voltadas aos problemas da mobilidade, e como ela pode articular-se com outras áreas para subsidiar ou produzir intervenções interdisciplinares eficazes. A resenha aqui descrita contempla informações sobre como está organizada a obra e os temas discutidos nos 23 capítulos, além de uma análise crítica das características do livro. A obra, ainda não traduzida para a língua portuguesa, representa uma importante publicação na área de trânsito, transporte e qualidade de vida, por considerar aspectos psicológicos subjacentes ao uso do automóvel e indicar possibilidades de contribuição da psicologia para o desenvolvimento de estratégias de gerenciamento de demanda de tráfego ${ }^{2}$.

A primeira parte do livro destaca os impactos negativos do uso do automóvel, indicando os desafios para se melhorar a qualidade de vida das pessoas nos grandes centros urbanos. As consequências indicadas vão além dos acidentes de trânsito, que talvez sejam os aspectos mais pesquisados e divulgados pela mídia. Os seis capítulos inseridos nesta seção discutem que o uso excessivo do automóvel pode acarretar: (a) danos ambientais - poluição atmosférica, acidificação e degradação de edifícios históricos e monumentos; (b) danos à saúde - sedentarismo, alergias, irritações do sistema respiratório e, em alguns casos, morte por doenças cardíacas e pulmonares; (c) redução da qualidade de vida - perturbação da atenção, da comunicação interpessoal e do sono, e potencialização de respostas afetivas e emocionais das pessoas frente aos problemas do trânsito, em decorrência do barulho advindo do tráfego; (d) dificuldade para representar cognitivamente o espaço urbano - utilização restrita do espaço urbano, que pode prejudicar os processos de localização, espacialidade e compreensão da estrutura e da forma urbana; (e) redução da utilização de ambientes restauradores diminuição do uso de espaços urbanos em que os indivíduos possam renovar suas capacidades psicológicas e fisiológicas desgastadas com as demandas cotidianas; e, finalmente, (f) aumento das externalidades - congestionamentos e elevados índices de acidentes.

Na segunda parte da obra, são apresentados alguns conceitos classicamente investigados pela psicologia social e ambiental (valores, crenças, atitudes, motivação e hábito), relacionando-os aos problemas do uso do automóvel. É a parte da obra que mais enfatiza a aplicação da psicologia na abordagem do trânsito e dos transportes, que são temas tradicionalmente estudados por outras áreas de investigação, especialmente a engenharia. É composta por sete capítulos que discutem fatores individuais e sociais que determinam e impactam o uso do automóvel, e que devem ser considerados ao se elaborar políticas de gerenciamento de demanda de tráfego: (a) padrão de atividades - ações cotidianas que as pessoas precisam realizar destinos para os quais precisam se deslocar, flexibilidade de tempo, dentre outros; (b) comportamento de viagem dos usuários - a maneira como as pessoas realizam suas atividades cotidianas, em termos de utilidade das atividades que demandam viagens, desempenho na realização da atividade e conteúdo social das viagens; (c) grau de dependência do automóvel - índice de utilização e intenção em reduzir o uso do automóvel; (d) motivação instrumental para o uso do automóvel - atribuição do uso do automóvel à necessidade de realização de atividades cotidianas; (e) outras motivações para o uso do automóvel - afetiva (vinculada à sensação de controle, liberdade e independência decorrentes do uso do automóvel) e simbólica (evidenciada pelo status atribuído ao uso do automóvel); (f) hábito de utilizar o automóvel - redução ou eliminação de qualquer deliberação sobre a escolha de modos 
alternativos de transporte, decorrentes da formação do hábito em usar o carro; e (g) crença em normas ecológicas - orientação pró ou anti-ambiental das pessoas.

$\mathrm{Na}$ terceira e última parte, nove capítulos apresentam estratégias para reduzir o uso do automóvel, em que o comportamento é considerado uma variável fundamental a ser considerada. As estratégias indicadas são: (a) desenho de formas urbanas sustentáveis - que viabilizem a redução do tempo para realizar os percursos e a disponibilização de modos de transporte mais sustentáveis que o automóvel; (b) implantação de medidas coercitivas - caracterizadas pela proibição do tráfego de automóveis em locais e horários específicos (por ex., restrição do acesso a estacionamentos e regiões centrais da cidade); (c) desenvolvimento de medidas de pricing - definição de tarifas para a utilização do automóvel conforme, por exemplo, a distância percorrida ou o horário em que é utilizado; (d) implantação de medidas não coercitivas - conscientização e aumento de informações transmitidas aos usuários por meio de estratégias de marketing individual e de campanhas educativas; (e) ações de marketing social - programas delineados para influenciar voluntariamente comportamentos específicos (por ex., uso da bicicleta e do transporte coletivo) ou uma audiência específica (por ex., funcionários de uma determinada empresa); (f) uso de sistemas inteligentes de transporte para motoristas, seja no interior do veículo (por ex., Global Position System - GPS) ou ao longo da via (por ex., painéis eletrônicos com informações sobre as condições de tráfego).

Considerando os conteúdos abordados em cada parte do livro, avalia-se que ele contempla vários problemas decorrentes do uso do automóvel, apresentando argumentos baseados em pesquisas empíricas e em relatos de intervenções governamentais. As diferentes perspectivas dos problemas, causas e soluções para o aumento da demanda pelo automóvel devem ser diagnosticadas para que sejam tomadas decisões acerca dos comportamentos a serem modificados e de quais medidas devem ser implantadas.

Além de proporcionar uma visão compreensiva dos problemas resultantes do uso do automóvel, bem como as causas desses problemas e as maneiras para administrá-los, também apresenta, ao final de cada capítulo, as limitações das pesquisas realizadas. Indica, também, teorias e métodos de investigação que abrangem a problemática da sustentabilidade nos transportes e o uso do automóvel; e aponta várias questões de pesquisa a serem exploradas, o que possibilita identificar os desafios e as limitações do que tem sido debatido no contexto internacional.

Algumas características desta obra, todavia, podem frustrar os leitores ou dificultar a sua leitura e compreensão, especialmente os menos acostumados a essas discussões, como o profissional iniciante na área. Como os textos refletem, em sua maioria, o contexto europeu e norte-americano, algumas especificidades desses países quanto ao tema discutido tornam a leitura, por vezes, complexa e de difícil compreensão, por não fazerem parte da realidade latino-americana.

A abordagem multidisciplinar, embora bastante necessária, também traz dificuldades aos leitores em determinados momentos, principalmente no que se refere ao uso de terminologias e metodologias muito específicas de cada área. Alguns conceitos e teorias apresentados não são explicados com clareza ou são difíceis de compreender de imediato, requerendo, em alguns casos, leituras complementares ao livro. Incluem-se, aqui, também alguns conceitos e teorias da psicologia que são aplicados aos problemas da mobilidade, não usados ainda, até onde sabemos, em pesquisas brasileiras, como a aceitabilidade e o hábito. A quantidade de informações dispostas em cada capítulo, embora seja uma característica positiva, traz certa sobrecarga ao leitor, uma vez que a leitura torna-se muito densa em determinados momentos. Parte dessas dificuldades está relacionada ao fato de o livro tentar oferecer um panorama geral da situação atual das pesquisas e intervenções a partir de capítulos curtos. Outra parte desses problemas pode ser atribuída, talvez, a uma suposição implícita por parte de alguns autores de que o leitor já conhece bem o assunto apresentado, o que faz com que certos aspectos não sejam detalhados.

De certa forma, tais dificuldades na leitura deste livro nos ajudaram a reconhecer que a psicologia tem muito a contribuir na resolução de problemas da área de mobilidade urbana, no sentido de intervir e trabalhar em conjunto com outras áreas, contribuindo para a produção de conhecimento técnico (teorias e métodos) e para a elaboração de políticas públicas. Igualmente, tais dificuldades reforçaram nosso entendimento da natureza interdisciplinar dos problemas da mobilidade, demonstrando como poderá ser, no futuro, o padrão do planejamento e das intervenções na área de trânsito e de transportes.

Por fim, o livro aqui apresentado e analisado pode servir como fonte de conhecimento e inspiração para o desenvolvimento de pesquisas, intervenções profissionais e políticas públicas, especialmente quando se vislumbra, a curto prazo, a ocorrência de grandes eventos que necessitam ser bem planejados e administrados do ponto de vista do transporte urbano, como a Copa do Mundo de 2014 e as Olimpíadas de 2016, e, a médio prazo, a efetivação da recém-instituída Política Nacional de Mobilidade Urbana.

\section{Referências}

Gärling, T., \& Steg, L. (Orgs.) (2007). Threats from car traffic to the quality of urban life: Problems, causes and solutions. Oxford: Elsevier.

Victoria Transport Policy Institute (2011). Online TDM Encyclopedia. Recuperado de http://www.vtpi.org 
1. Tradução sugerida: Ameaças do tráfego de automóveis para a qualidade de vida urbana: Problemas, causas e soluções. Resenhas de cada capítulo do livro podem ser acessadas em www.portalpsitran.com.br.

2. Políticas de gerenciamento de demanda de tráfego buscam modificar o comportamento de viagem dos indivíduos, gerando eficiência nos deslocamentos e diminuição dos custos envolvidos (Victoria Transport Policy Institute, 2011).

Ingrid Luiza Neto, Mestre em Psicologia Social, do Trabalho e das Organizações pela Universidade de Brasília - UnB, doutoranda em Psicologia Social, do Trabalho e das Organizações pela Universidade de Brasília - UnB. Endereço para correspondência: SMPW quadra 28 conjunto 1 lote 7, Park Way. Brasília DF, CEP: 71745-801. Email: ingridluizaneto@gmail.com

Zuleide Oliveira Feitosa, Mestre em Psicologia Social, do Trabalho e das Organizações pela Universidade de Brasília - UnB, é professora no Seminário Presbiteriano de Brasília - Mackenzie. Email: zuleideoliveira@ yahoo.com.br

Fabio de Cristo, Mestre em Psicologia pela Universidade Federal do Rio Grande do Norte (UFRN), é professor do Centro Universitário de Brasília (UniCEUB) e do Instituto de Educação Superior de Brasília (IESB). Email: fabiodecristo@gmail.com

Clara Cantal, Mestre em Psicologia Social, do Trabalho e das Organizações pela Universidade de Brasília, candidata ao título de doutorado em Psicologia pela Universidade Victoria de Wellington, Nova Zelandia. Email: claracantal@gmail.com

Hartmut Günther, Pós-Doutor pela City University of New York, Pós-Doutor pela Michigan State University, Doutor em Psicologia pela University of California at Davis, UCD, é professor titular no Instituto de Psicologia da Universidade de Brasília e coordenador do Laboratório de Psicologia Ambiental. Email: hartmut.gunther@me.com 